\title{
수소동위원소 저장용 $\mathrm{ZrCo}$ 용기의 급속 냉각 성능 평가
}

\author{
이정민 ${ }^{1} \cdot$ 박종철 ${ }^{1} \cdot$ 구대서 ${ }^{1} \cdot$ 정동유 $^{2} \cdot{\text { 윤세 } \overline{ }^{2}}^{2} \cdot$ 백승우 $^{1} \cdot$ 정흥석 $^{1 \dagger}$
}

${ }^{1}$ 한국원자력연구원 핵주기공정개발부, ${ }^{2}$ 국가핵융합연구소 ITER한국사업단

\author{
Rapid Cooling Performance Evaluation of a ZrCo bed \\ for a Hydrogen Isotope Storage \\ JUNGMIN LEE ${ }^{1}$, JONGCHUL PARK ${ }^{1}$, DAESEO KOO ${ }^{1}$, DONGYOU CHUNG ${ }^{2}$, SEI-HUN YUN ${ }^{2}$, \\ SEUNGWOO PAEK ${ }^{1}$, HONGSUK CHUNG $^{1 \dagger}$ \\ ${ }^{1}$ KAERI, 989-111 Daedeokdaero, Yuseong, Daejeon 305-353, Korea \\ ${ }^{2}$ NFRI, 113 Gwahakro, Yuseong, Daejon 305-353, Korea
}

\begin{abstract}
The nuclear fuel cycle plant is composed of various subsystems such as a fuel storage and delivery system (SDS), a tokamak exhaust processing system, a hydrogen isotope separation system, and a tritium plant analytical system. Korea is sharing in the construction of the International Thermonuclear Experimental Reactor (ITER) fuel cycle plant with the EU, Japan, and the US, and is responsible for the development and supply of the SDS. Hydrogen isotopes are the main fuel for nuclear fusion reactors. Metal hydrides offer a safe and convenient method for hydrogen isotope storage. The storage of hydrogen isotopes is carried out by absorption and desorption in a metal hydride bed. These reactions require heat removal and supply respectively. Accordingly, the rapid storage and delivery of hydrogen isotopes are enabled by a rapid cooling and heating of the metal hydride bed. In this study, we designed and manufactured a vertical-type hydrogen isotope storage bed, which is used to enhance the cooling performance. We present the experimental details of the cooling performances of the bed using various cooling parameters. We also present the modeling results to estimate the heat transport phenomena. We compared the cooling performance of the bed by testing different cooling modes, such as an isolation mode, a natural convection mode, and an outer jacket helium circulation mode. We found that helium circulation mode is the most effective which was confirmed in our model calculations. Thus we can expect a more efficient bed design by employing a forced helium circulation method for new beds.
\end{abstract}

Key words : Nuclear fusion energy(핵융합), Storage and delivery bed(수소저장용기), Hydrogen isotope(수소동위 원소), Metal hydride(금속수소화물), Zirconium cobalt(지르코늄 코발트)

\section{1. 서 론}

에너지 수요가 점차 증가하면서 고효율의 에너지

\footnotetext{
${ }^{\dagger}$ Corresponding author : hschung1@kaeri.kr [ 접수일 : 2013.3 .19 수정일 : 2013.4.24 게재확정일 : 2013.4.26 ] Copyright (c) 2013 KHNES
}

를 발생하는 에너지 발전 기술의 필요성은 증가하고 있다. 이에 따라 핵융합 반응에 대한 관심은 점차 증 가 하고 있으며 원자력 발전과 비교하여 핵융합발전 은 고준위 방사선 폐기물을 전혀 발생하지 않는 중 요한 미래 에너지원이다 ${ }^{1-5)}$. 삼중수소, 중수소는 수소 의 동위원소이며 미래의 핵융합 발전의 연료로 사용 
된다. 특히 삼중수소에 대한 관심이 높아지고 있는 상 황이다. 핵융합 에너지를 획득하기 위한 핵융합로에 서는 운전 시나리오에 따른 많은 양의 수소 동위원소 를 안전하게 저장, 공급하는 기술이 요구되고 있다. 이 에 따라 수소동위원소를 저장하는 방법으로 금속수 소화물(metal hydride)인 감손 우라늄(depleted uranium) 과 지르코늄 코발트(zirconium cobalt)를 이용한 방법 이 제안되고 있다 ${ }^{6-8)}$. 수소동위원소는 저장재와 화학 적인 반응을 통하여 금속수소화물을 형성하며 안정 한 상태로 저장이 되지만 반응열을 수반한다. 따라서 저장용기의 운전 시나리오에 맞추어 볼 때, 수소동위 원소의 빠른 저장을 위해서는 급속 냉각 기술이 필 요하며 반대로 금속수소화물에서 수소동위원소를 빠 르게 분리하기 위해서는 급속 가열 기술이 필요하다. 현재 급속 가열 기술로는 히터를 사용한 가열이 지 배적이지만 빠른 저장을 위한 급속 냉각 시술에 대 하여서 여러 의견이 나오고 있는 상황이다 ${ }^{9-11)}$. 따라 서 본 연구에서는 금속수화물 중 비교적 안정성이 증 명된 지르코늄 코발트를 이용하여 급속 냉각이 가능 한 수직형 수소동위원소 저장 용기를 설계, 제작 ${ }^{(12)}$ 하였으며 히터를 이용하여 저장용기의 온도를 $500^{\circ} \mathrm{C}$ (히터 기준)까지 승온 시킨 후 여러 냉각 기술들을 이 용하여 냉각 성능을 평가 하였다.

\section{2. 수직형 $\mathrm{ZrCo}$ 저장용기 냉각 성능 평가}

\section{1 수직형 $\mathrm{ZrCo}$ 저장용기}

Fig. 1은 수직형 $\mathrm{ZrCo}$ 저장용기의 단면도이다. 저 장용기는 1 차 용기와 2 차 용기로 나눌 수 있다. 1 차 용기는 저장재인 $\mathrm{ZrCo}$, 수소(수소동위원소)유입 및 유출라인과 헬륨 루프(helium-loop), 가열기(heater), 진공라인, 필터, 온도 및 압력 측정 장치 등으로 구성 되어 있다.

2 차 용기는 1차 용기를 감싸고 있는 원통형 모양 의 구조이다. 2 차 용기는 내부에 위치한 1 차 용기를 보호하며, 비상시 수소 가스의 외부 유출을 막아주는 역할과 냉각 시에는 $\mathrm{He}$ 이 2차 용기 안으로 들어가

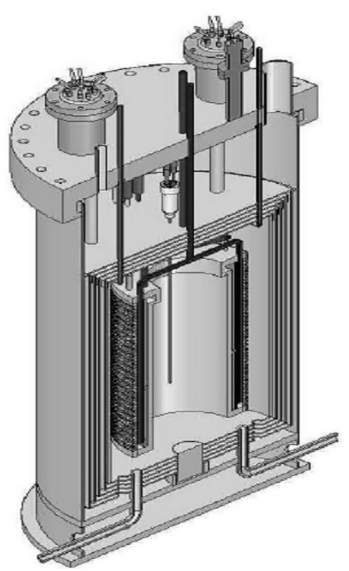

Fig. 1 Cross-section of the vertical type ZrCo bed

뜨거워진 1차 용기의 열 손실을 유도하여 냉각 효과 를 내는 목적으로 설계하였다.

\section{2 이론적 냉각 성능 평가}

수직형 $\mathrm{ZrCo}$ bed의 지배방정식은 다음과 같다 ${ }^{13)}$.

- Continuity Equation.

$\frac{1}{r} \frac{\partial\left(r \rho v_{r}\right)}{\partial r}+\frac{\partial\left(\rho v_{z}\right)}{\partial z}+\frac{\partial \rho}{\partial t}=0$

- Momentum of r-direction

$\rho\left(\frac{\partial v_{r}}{\partial t}+v_{r} \frac{\partial v_{r}}{\partial r}+v_{z} \frac{\partial v_{z}}{\partial z}\right)=$

$-\frac{\partial P}{\partial r}+\mu\left(\frac{\partial^{2} v_{r}}{\partial r^{2}}+\frac{1}{r} \frac{\partial v_{r}}{\partial r}-\frac{v_{r}}{r^{2}}+\frac{\partial^{2} v_{r}}{\partial z^{2}}\right)$

- Momentum of z-direction

$\rho\left(\frac{\partial v_{z}}{\partial t}+v_{r} \frac{\partial v_{r}}{\partial r}+v_{z} \frac{\partial v_{z}}{\partial z}\right)=$

$-\frac{\partial P}{\partial z}+\mu\left(\frac{\partial^{2} v_{z}}{\partial r^{2}}+\frac{1}{r} \frac{\partial v_{z}}{\partial r}+\frac{\partial^{2} v_{z}}{\partial z^{2}}\right)+\rho g$

- Energy equation

$\alpha\left(\frac{\partial T}{\partial t}+v_{r} \frac{\partial T}{\partial r}+v_{z} \frac{\partial T}{\partial z}\right)=$ 
$\mathrm{r}$-반지름 방향

$\mathrm{z}$-높이 방향

$\mathrm{t}$-시간항

$\rho$-밀도

$\mathrm{v}$-속도

P-압력

$\mathrm{T}$-온도

$\mathrm{g}$-중력가속도

$\mu$-점도

a-열확산도 $\left(\rho C_{p} / k\right)$

여기에 적용한 가정은 다음과 같다.

(1) $\theta$ 방향으로의 온도 및 속도 변화는 무시한다.

(2) 복사의 경우 원통의 옆면과 위·아래 면의 2가 지로 나누어서 계산을 진행하였다.

(3) 자연대류에서 원통 옆면과 위의 대류효과만 계 산하고 밑의 부분의 대류 효과는 무시하였다.

(4) 온도 계산은 복사열전달의 계산 항이 포함되 기 때문에 절대 온도를 사용하였다.

(5) 내부 실린더의 표면 온도는 시간에 따라서만 변하며, 같은 시간대에서는 모든 지점에서 같 은 온도값을 가진다.

1 차 용기의 냉각에 대한 열전달 기본 식은 다음과 같이 나타낼 수 있다.

$\rho_{s t} C_{p, s t} V_{c y l} \frac{\partial T}{\partial t}=$

$h A\left(T_{s}-T_{\infty}\right)+F_{12} A \epsilon \sigma\left(T_{s}^{4}-T_{\infty}^{4}\right)+\dot{Q_{c o n d}}$

$\rho_{s t}$-철의 밀도

$C_{p . s t}$-철의 열용량

$V_{c y l}$-내부 실린더의 부피

$\mathrm{h}$-대류 열전달 계수

$\mathrm{A}$-단면적

$F_{12}$-관측계수(view factor)

$\varepsilon$-방사도

$\sigma$-Boltzmann 상수 $\left(5.67 \times 10^{-8} \mathrm{~W} / \mathrm{m}^{2} \cdot \mathrm{K}^{4}\right)$

$Q_{\text {cond }}$-전도 열손실양
복사 열전달의 경우 원통 옆면과 위·아래 두 가지 로 나누어서 계산을 하였다 ${ }^{14)}$.

- Side:

$\dot{Q}_{12}=\frac{\sigma\left(T_{1}^{4}-T_{2}^{4}\right)}{\frac{1-\epsilon_{1}}{A_{1} \epsilon_{1}}+\frac{1}{A_{1} F_{12}}+\frac{1-\epsilon_{2}}{A_{2} \epsilon_{2}}}$

- Top \& Bottom:

$\dot{Q}_{12}=F_{12} A_{1} \epsilon \sigma\left(T_{1}^{4}-T_{2}^{4}\right)$

자연 대류 열전달 식의 경우에도 원통 옆면과 위 아래 두 가지로 나누어서 계산을 하였다 ${ }^{15)}$.

- Side:

$N u=0.253\left(R a^{*}\right)^{0.244}$,

$R a^{*}=\frac{g \beta\left(T_{s}-T_{\infty}\right)\left(D_{o}-D_{i}\right)^{4}}{\nu^{2} L} \operatorname{Pr}$

v-동점도(kinematic viscosity)

$\beta$-열팽창도

$\mathrm{D}_{\mathrm{o}}$-외부직경,

$\mathrm{D}_{\mathrm{i}}$-내부직경

L-실린더높이

$\mathrm{g}$-중력가속도

-Top \& Bottom:

$$
\begin{aligned}
& N u=0.195 R a^{0.25}, \\
& R a=\frac{g \beta\left(T_{s}-T_{\infty}\right)\left(D_{o}-D_{i}\right)^{3}}{\nu^{2}} \operatorname{Pr}
\end{aligned}
$$

외부 자켓 순환의 경우 $\mathrm{Gr} / \mathrm{Re}^{2}$ 값이 0.1 에서 10 사 이의 값을 가지게 된다. 따라서 여기에서는 자연대류 와 강제대류를 모두 고려해야만 한다. 때문에 이 경 우 위의 자연대류의 항에 다음의 강제대류 식의 열 전달 계수 항을 더하여 적용하였다 ${ }^{14,16)}$.

$$
N=0.086 R e^{0.62}, \quad R e=\rho D v / \mu
$$


Table 1 Rapid cooling condition

\begin{tabular}{|c|c|c|c|c|}
\hline Mode & $1^{\text {st }}$ vessel & $2^{\text {nd }}$ vessel & Helium-loop & Temperature \\
\hline lsolation & $\begin{array}{c}\text { Continuous } \\
\text { vacuum }\end{array}$ & $\begin{array}{c}\text { Continuous } \\
\text { vacuum }\end{array}$ & $\begin{array}{c}\text { No } \\
\text { operating }\end{array}$ & \multirow{5}{*}{$500^{\circ} \mathrm{C}$} \\
\hline \multirow{2}{*}{$\begin{array}{c}\text { Natural } \\
\text { convection }\end{array}$} & \multirow{2}{*}{$\begin{array}{c}\text { Continuous } \\
\text { vacuum }\end{array}$} & 380 torr & \multirow{2}{*}{$\begin{array}{c}\text { No } \\
\text { operating }\end{array}$} & \\
\hline & & 760 torr & & \\
\hline \multirow{2}{*}{$\begin{array}{l}\text { Outerjacket } \\
\text { circulation }\end{array}$} & \multirow{2}{*}{$\begin{array}{c}\text { Continuous } \\
\text { vacuum }\end{array}$} & $\begin{array}{c}380 \text { torr } \\
\text { (circulation) }\end{array}$ & \multirow{2}{*}{$\begin{array}{c}\text { No } \\
\text { operating }\end{array}$} & \\
\hline & & $\begin{array}{c}760 \text { torr } \\
\text { (circulation) }\end{array}$ & & \\
\hline
\end{tabular}

실린더 내부에서의 유체의 속도는 다음의 식을 이 용하여 계산하였다.

$$
\rho_{1} v_{1} A_{1}=\rho_{2} v_{2} A_{2}
$$

압력강하 효과의 경우 계산 결과 그 효과가 미미 하였기 때문에 여기에서는 무시하기로 하였다.

\section{3 냉각 실험 조건}

Table 1은 수직형 저장용기의 급속 냉각 실험 조 건이다. 1 차 용기 외벽에 연결 되어 있는 heater를 이 용하여 $500^{\circ} \mathrm{C}$ 로 1 차 용기를 가열한 후 냉각 조건에 따라 실험을 진행하여 heater의 온도가 $30^{\circ} \mathrm{C}$ 에 도달 하는 시간을 측정하여 급속 냉각 성능을 평가 하였 다. 실험 조건의 isolation mode(진공자연냉각)는 수 소동위원소 저장 용기가 단열이 된 상태에서의 자연 냉각능력을 평가 하고자 하였다. 1,2 차 용기는 진공 상태를 유지하도록 하여 자연 냉각을 진행 하였다.

Natural convection mode(자연대류냉각)는 현재 수 소동위원소 저장 용기의 운전 시나리오에서 냉각을 위한 방법으로 사용되고 있는 기본적인 냉각 방법이 다. 1 차 용기는 진공 상태를 유지하면서 2차 용기에 $\mathrm{He}$ 을 380, 760torr의 압력으로 넣어 주어 2차 용기의 $\mathrm{He}$ 의 양에 따른 냉각 성능을 평가 하였다.

Outer jacket circulation mode(순환냉각)의 경우 저 장 용기의 냉각 성능을 높이고자 제작한 수직형 저 장용기의 특징으로 자연대류 방식에서 2차 용기에 들 어 있는 $\mathrm{He}$ 을 기체 펌프(metal bellows-302 pump)와

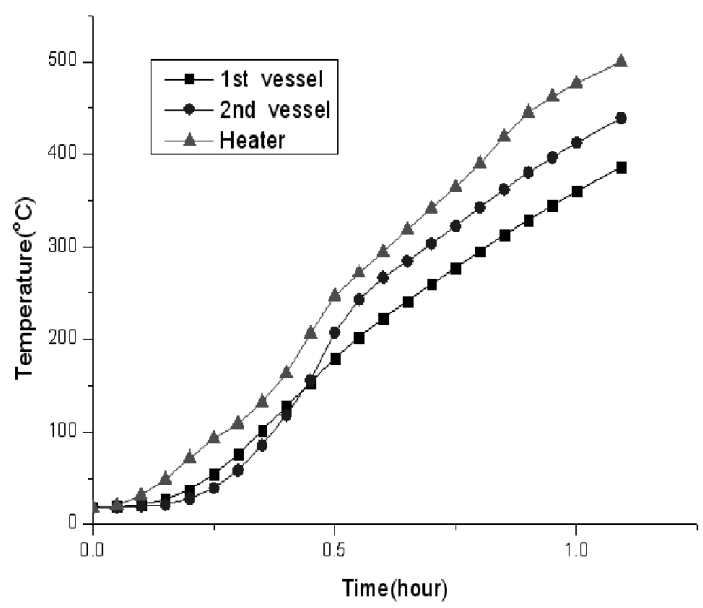

Fig. 2 Experimental conditions of the heater

열교환기(heat exchanger)를 이용하여 일정한 온도와 저온으로 순환 하도록 하여 냉각 성능을 평가 하였다.

\section{3. 실험 결과}

\section{1 냉각 실험을 위한 저장용기 가열}

Fig. 2는 냉각 실험을 위하여 저장용기 내에 연결 되어 있는 가열기를 이용하여 저장 용기를 가열한 결과이다. 실제 저장용기의 운전 시나리오에서의 냉 각 과정과 본 연구에서의 냉각 실험 조건이 최대한 유사하게 진행 되도록 하였다. Heater를 1시간 이상 서서히 $500^{\circ} \mathrm{C}$ 로 승온 뒤 10 분간 $500^{\circ} \mathrm{C}$ 를 유지 하도 록 하여 bed 전체에 열전달이 되도록 하였으며 히터 및 베드(bed)의 온도 상태를 확인한 후 실험을 진행 하였다.

\section{2 자연 냉각}

Fig. 3는 진공자연냉각 실험의 결과이다. 외부 영 향 없이 오직 진공 상태에서 자연 냉각만을 이용하 였기에 온도별 냉각 소요시간을 살펴보면 $500^{\circ} \mathrm{C}$ 에서 $400^{\circ} \mathrm{C}$ 까지 27 분 $300^{\circ} \mathrm{C}$ 까지는 1 시간 53 분, $200^{\circ} \mathrm{C}$ 까지 는 6 시간 35 분, $100^{\circ} \mathrm{C}$ 까지는 21 시간 31 분, 마지막 3 $0{ }^{\circ} \mathrm{C}$ 까지는 72 시간 42 분이 걸리는 것을 확인 할 수 있 


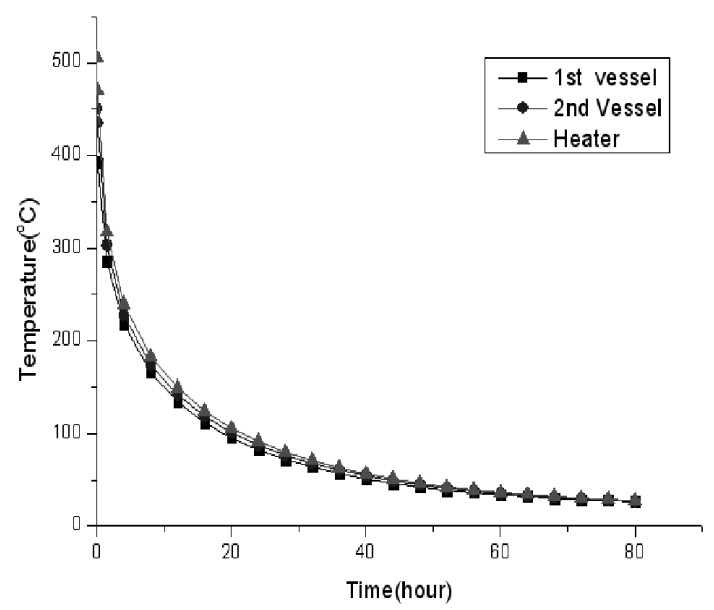

Fig. 3 Temperature changes during Isolation mode

었다. 이 결과를 바탕으로 하여 나머지 냉각 변수들에 의한 냉각 시간을 비교 하여 냉각 성능을 평가 하였다.

\section{3 자연 대류}

자연 대류의 경우 2 차 용기에 $\mathrm{He}$ 을 채워서 자연 대류에 의한 냉각 효과를 기대 하였다.

Fig. 4는 자연 대류 실험의 $\mathrm{He}$ 이 380 torr 또는 760torr 채워져 있는 조건의 냉각 결과이다. He 380 torr의 경우, 온도별 냉각 소요시간은 $400^{\circ} \mathrm{C}$ 까지 15 분 $300^{\circ} \mathrm{C}$ 까지는 47 분, $200^{\circ} \mathrm{C}$ 까지는 1 시간 50 분, $100^{\circ} \mathrm{C}$ 까지는 4 시간 7 분, $30^{\circ} \mathrm{C}$ 까지는 10 시간 41 분으로 총 냉각 소요시간이 10 시간 41 분 걸리는 것을 확인 할 수 있었다.

한편 He 760torr의 경우, 온도별 냉각 소요시간은 $400^{\circ} \mathrm{C}$ 까지 16 분 $300^{\circ} \mathrm{C}$ 까지는 52 분, $200^{\circ} \mathrm{C}$ 까지는 1 시 간 58 분, $100^{\circ} \mathrm{C}$ 까지는 4 시간 17 분, $30^{\circ} \mathrm{C}$ 까지는 10 시 간 36 분으로 자연 냉각을 유도했던 진공자연냉각의 결과와 비교 하였을 때, 자연 대류에 의한 냉각 효 과가 더 뛰어남을 확인 할 수 있었다. 하지만 $\mathrm{He}$ 이 380 torr 채워져 있는 조건과 비교 하였을 때 자연 대 류에서 $\mathrm{He}$ 의 양에 따른 냉각 성능의 차이는 크게 나 지 않는 것을 확인 할 수 있었다. 이는 $\mathrm{He}$ 이 2 차 용 기 안에서 어떠한 흐름 없이 공간만을 차지하고 있

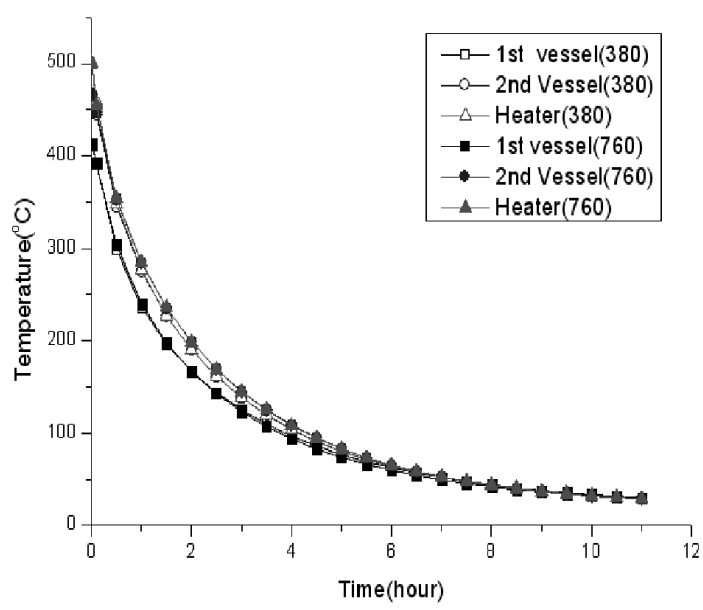

Fig. 4 Temperature changes during natural convection mode helium 380 torr and 760 torr

는 고정된 상태이기 때문에 1차 저장 용기와 거리가 먼 $\mathrm{He}$ 까지 열전달이 제대로 이루어지지 않아 $\mathrm{He}$ 의 양에 따른 성능은 미비한 것으로 생각 되어 진다.

\section{4 순환 냉각}

수직형 저장용기의 냉각 특징으로 펌프를 이용하 여 강제 대류에 의한 냉각이 가능하도록 하여 기존 의 냉각 방식과 비교하고자 하였다.

Fig. 5는 순환 냉각 실험의 He이 380torr 또는 760 torr가 순환하는 조건의 냉각 결과이다. He 380 torr 의 경우, 온도별 냉각 소요시간을 살펴보면 $400^{\circ} \mathrm{C}$ 까 지 10 분 $300^{\circ} \mathrm{C}$ 까지는 30 분, $200^{\circ} \mathrm{C}$ 까지는 1 시간 12 분, $100^{\circ} \mathrm{C}$ 까지는 2 시간 56 분, 마지막 $30^{\circ} \mathrm{C}$ 까지는 8 시간 31 분으로 진공자연냉각 또는 자연 대류에 의한 냉각 과 비교 하였을 때 각 각 64 시간 11 분, 약 2 시간 7 분 의 냉각 시간을 단축하는 것을 알 수 있었다.

한편 He 760torr의 경우, 온도별 냉각 소요시간은 $400^{\circ} \mathrm{C}$ 까지 12 분 $300^{\circ} \mathrm{C}$ 까지는 35 분, $200^{\circ} \mathrm{C}$ 까지는 1 시 간 14 분, $100^{\circ} \mathrm{C}$ 까지는 2 시간 31 분, 마지막 $30^{\circ} \mathrm{C}$ 까지는 6 시간 21 분으로 $\mathrm{He}$ 이 380 torr 일 때의 조건과 $100^{\circ} \mathrm{C}$ 까지의 냉각 소요시간은 크게 차이가 나지 않지만 총 냉각 소요 기간에서는 2 시간 정도 단축되는 것을 확인 할 수 있었다. 이는 헬륨이 각기 다른 압력과 온 


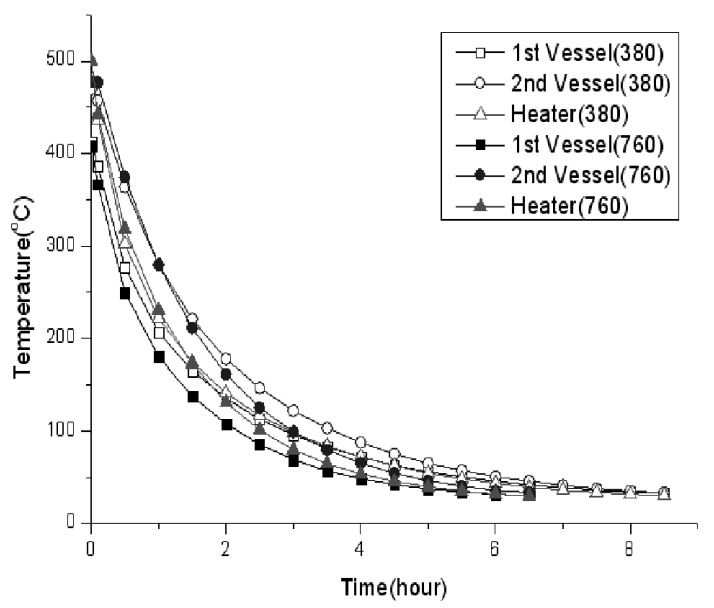

Fig. 5 Temperature changes during outer jacket circulation mode helium 380 torr and 760 torr

도에서 상이한 열전달계수를 가지기 때문에 나타나 는 현상이다.

Table 2는 지금 까지 수행한 냉각 성능 평가 실험 의 결과들을 종합하여 보았다. 이 결과들을 바탕으로 순환냉각 방식의 냉각 성능이 뛰어난 이유는 pump로 인하여 형성된 강제 대류효과로 지속적으로 움직이 는 $\mathrm{He}$ 에 열이 골고루 전달되었고 열교환기를 통하여 1 차 용기의 열을 전달 받은 고온의 $\mathrm{He}$ 이 냉각 되어 다시 순환하기 때문에 냉각 성능이 가장 뛰어난 것 으로 생각 되어 진다.

\section{5 모델링 모사 결과}

수직형 저장용기의 제작 초기에 세웠던 이론적 내 용을 통해 얻은 모사 결과를 실제 실험 결과와 비교 하여 신뢰성을 확인 하고자 하였다. Fig. 6은 진공자

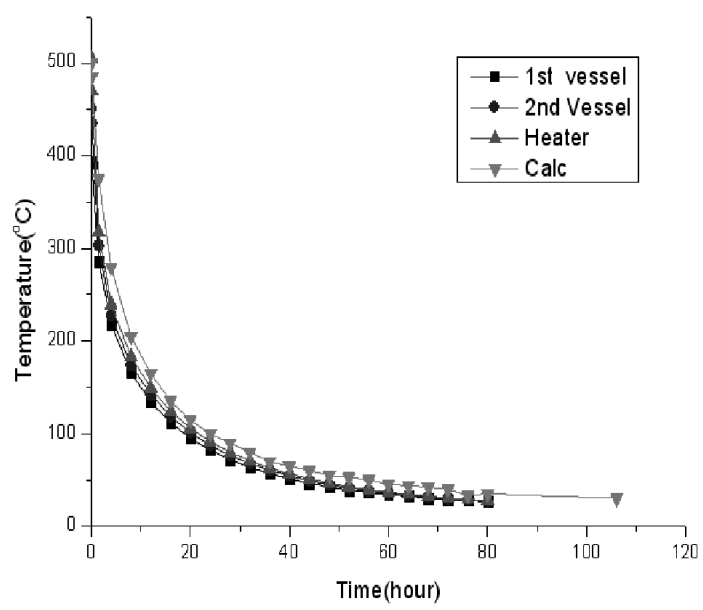

Fig. 6 Comparison of cooling temperature at Isolation mode

연냉각 실험에서의 비교 결과이다. 진공 상태에서의 자연 냉각이기 때문에 복사에 의한 열전달 효과만을 생각하였다.

실제 냉각 결과와 비교 하여 비슷한 경향성을 보 이는 것을 확인 할 수 있다.하지만 이론적 결과 보다 실제 실험 결과의 온도가 낮고 냉각시간이 짧게 나 타나는 것은 실제 실험과정에서 용기의 벽면과 진공 상태의 남아있는 미세 입자를 통한 열전도 현상이 발생되어 진 것으로 생각 되어 진다.

Fig. 7과 8은 자연대류냉각의 비교 결과이다. 전체 적인 냉각 결과를 비교 하였을 때 비슷한 경향성을 나타내기 때문에 실험 결과에 대한 신뢰성을 확인 할 수 있었다. He이 760torr 일 때의 이론적 결과 값이 실제 실험 결과와 상당히 유사한 이유는 이론적 배 경에서 단순 열전도뿐만 아니라 헬륨의 밀도와 다른 물성에 대한 값이 760torr(1기압)에서 유효한 값이기

Table 2 Results of rapid cooling experimental

\begin{tabular}{|c|c|c|c|c|c|c|}
\hline \multicolumn{2}{|c|}{ Mode } & $400\left({ }^{\circ} \mathrm{C}\right)$ & $300\left({ }^{\circ} \mathrm{C}\right)$ & $200\left({ }^{\circ} \mathrm{C}\right)$ & $100\left({ }^{\circ} \mathrm{C}\right)$ & $30\left({ }^{\circ} \mathrm{C}\right)$ \\
\hline \multicolumn{2}{|c|}{ lsolation } & 27분 & 1 시간 53 분 & 6 시간 35 분 & 21시간 31분 & 72 시간 43 분 \\
\hline \multirow{2}{*}{$\begin{array}{l}\text { Natural } \\
\text { convection }\end{array}$} & 380 torr & 15 분 & 47 분 & 1 시간 50 분 & 4시간 7 분 & 10 시간 41 분 \\
\hline & 760 torr & 16 분 & 52 분 & 1 시간 58 분 & 4 시간 17 분 & 10 시간 36 분 \\
\hline \multirow{2}{*}{$\begin{array}{l}\text { Outerjacket } \\
\text { circulation }\end{array}$} & 380 torr & 10 분 & 30 분 & 1 시간 12 분 & 2시간 56분 & 8 시간 31 분 \\
\hline & 760 torr & 12 분 & 35 분 & 1 시간 14 분 & 2 시간 31 분 & 6시간 21 분 \\
\hline
\end{tabular}




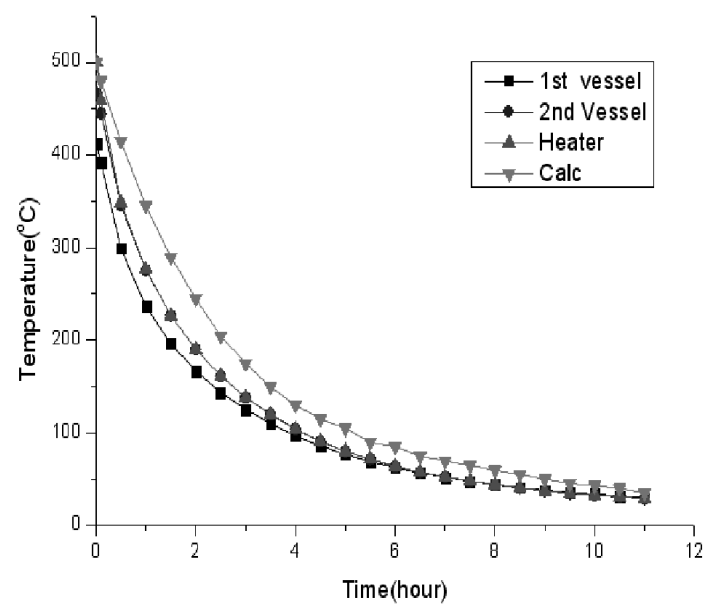

Fig. 7 Comparison of cooling temperature at natural convection mode helium 380 torr

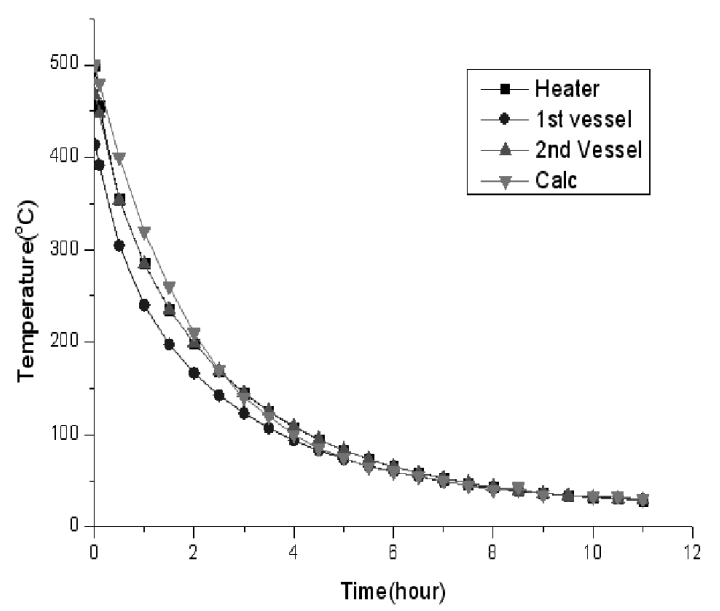

Fig. 8 Comparison of cooling temperature at natural convection mode helium 760 torr

에 비교적 정확한 값을 얻을 수 있었다.

Fig. 9와 10은 대류냉각의 비교 결과이다. 이론적 결과에서는 자연 대류, 강제 대류 및 복사를 전부 고 려하여 계산 하였다. 따라서 실험 결과와 경향성이 상당히 유사한 결과를 얻을 수 있었다.

\section{4. 결 론}

본 연구에서는 급속 냉각이 가능하도록 설계된 수 직형 수소 저장 용기를 바탕으로 여러 냉각 변수를

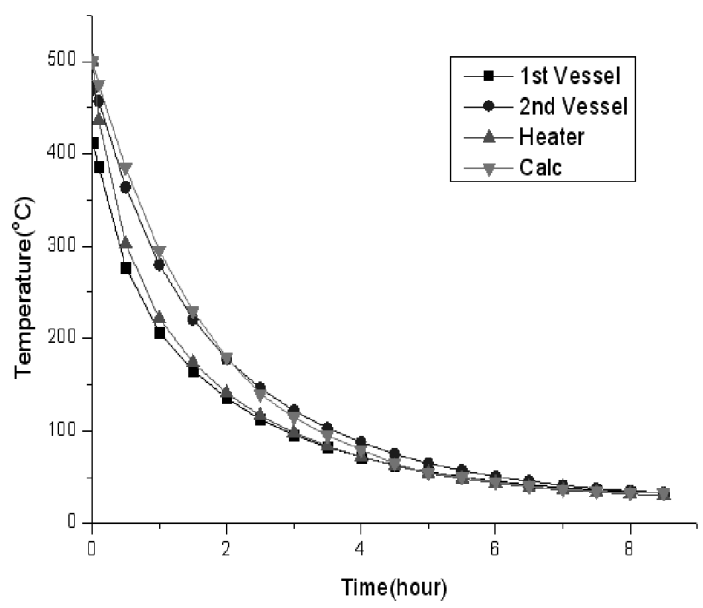

Fig. 9 Comparison of cooling temperature at outer jacket circulation mode helium 380 torr

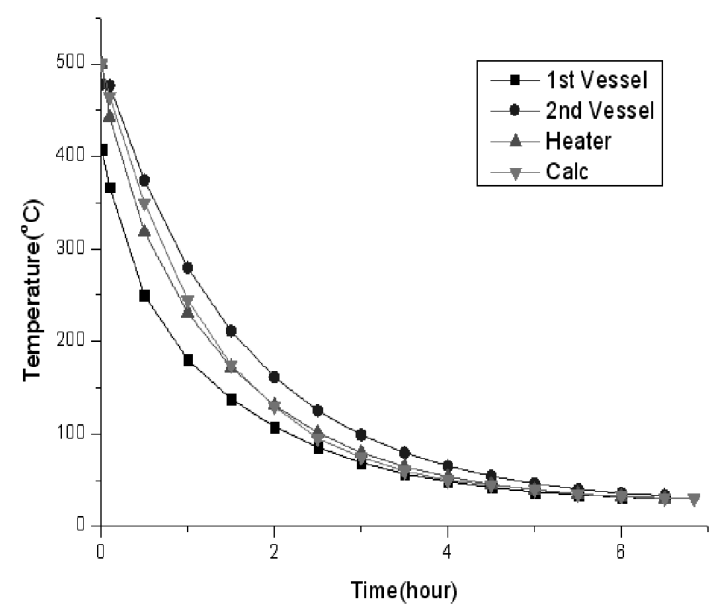

Fig. 10 Comparison of cooling temperature at outer jacket circulation mode helium 760 torr

이용하여 냉각 성능을 평가하고 이론적 접근을 통하 여 결과에 대한 신뢰성을 얻고자 하였다. 냉각 변수 를 크게 진공자연냉각, 자연 대류, 순환냉각으로 나 누어 비교 해보았을 때, $\mathrm{He}$ 을 순환 시켜 강제 대류의 형식을 이용한 냉각 방법이 가장 뛰어난 냉각 성능 을 나타냈으며 이론적 결과와 비슷한 경향성을 나타 내는 것을 확인 할 수 있었다. 따라서 본 연구의 결과 를 바탕으로 앞으로 기존의 수소 저장용기의 냉각 방식인 자연 대류보다 냉각 성능이 더 뛰어난 수소 저장용기를 제작 할 수 있을 것으로 기대되어 진다. 


\section{후 기}

본 연구는 미래창조과학부의 국제핵융합실험로 공 동개발사업(NRF 2013-000137) 및 국가핵융합연구소 의 지원으로 수행되었습니다.

\section{참 고 문 헌}

1. S. Cho, M. Chang, S. Yun, H. Kang, K. Jung, H. ongsuk Chung, D. Koo, Y. Kim, J. Lee, K. Song, S. Sohn, K. Kim, D. Kim, "ITER storage and delivery system R \& D in korea", IEEE Transactions on Plasma Science, Vol. 38, No. 3, 2010, pp. 425-433.

2. H. Chung, D. Chung, D. Koo, J. Lee, M. Shim, S. Cho, K. Jung, S. Yun, "Storage and Delivery of Hydrogen Isotopes", Trans. of the Korean Hydrogen and New Energy Society, Vol. 22, No. 3, 2011, pp. 372-379.

3. H. Chung, K. Kang, M. Chang, S. Cho, W. Kim, J. Nam, D. Kim, K. Song, S. Paek, D. Koo, D. Chung, J. Lee, C. Kim, K. Jung and S. Yun, "Safety Analysis of a Hydrogen Isotopes Process", Trans. of the Korean Society of Hydrogen Energy, Vol. 23, No. 3, 2012, pp. 219-226.

4. D. Koo, H. Chung, D. Chung, J. Lee, S. Yun, S. Cho and K. Jung, "Hydrogen Isotopes Accountancy and Storage Technology", Trans. of the Korean Society of Hydrogen Energy, Vol. 23, No. 1, 2012, pp. 49-55.

5. S. Yun, M. Chang, H. Kang, C. Kim, S. Cho, K. Jung, H. Chung and K. Song, "Tritium Fuel Cycle Technology of ITER Project", Trans. of the Korean Society of Hydrogen Energy, Vol. 23, No. 1, 2012, pp. 56-64.

6. H. Chung, M. Shim, H. Yoshida, H. Jin, J. Lee, D. Ahn, K. Kim, K. Song, D. Kim, M. Chang, H. Kang, S. Yun, S. Cho, "Korea's progress on the ITER tritium systems", Fusion Engineering and Design, Vol. 84, 2009, pp. 599-603.

7. M. Shim, H. Chung, S. Cho, H. Yoshida, "Dispro- portionation characteristics of a zirconium-cobalt hydride bed under ITER operating conditions", Fusion Science and Technology 53, 2008, pp. 830-840.

8. H. Chung, M. Shim, D. Ahn, M. Lee, C. Hong, H. Yoshida, K. Song, D. Kim, K. Jung, and S. Cho, "Korea's Activities for the Development of ITER Tritium Storage and Delivery Systems", Fusion Science and Technology, Vol. 54, 2008, p. 18.

9. M. Shim, H. Chung, H. Yoshida, H. Jin, M. Chang, S. Yun, and S. Cho, "Initial Test Results of a Fast Heat Transfer Response ZrCo Hydride Bed”, Fusion Science and Technology, Vol. 56, 2009, p. 857.

10. M. Shim, H. Chung, H. Yoshida, K. Kim, S. Cho, E. Lee, and M. Chang, "Experimental Study on the Delivery Rate and Recovery Rate of $\mathrm{ZrCo}$ Hydride for ITER Application", Fusion Science and Technology, Vol. 54, 2008, p. 27.

11. M. Shim, H. Chung, H. Yoshida, H. Jin, J. Lee, K. Song, M. Chang, H. Kang, S. Yun, and S. Cho, "Hydriding/dehydriding Characteristics on Fast Heat Transfer Response ZrCo Bed for ITER”, Fusion Engineering and Design, Vol. 84, 2009, p. 1763.

12. J. Lee, J. Park, D. Koo, D. Chung, H. Chung, "Cooling Characteristics of a Hydrogen Storage Bed”, Applied Chemistry, to be published, 2013.

13. R. B. Bird. W. E. Stewart. E. N. Lightfoot. "Transport Phenomena" 2nd Ed. John Wiley \& Sons, Inc. 2007.

14. Yunus A. Çengel. "Heat Transfer: A Practical Approach" 2nd Ed. McGraw-Hill. 2003.

15. R. Hosseini, A. Rezania, M. Alipour, L. A. Rosendahl, "Natural convection heat transfer from a long heated vertical cylinder to an adjacent air gap of concentric and eccentric conditions." Heat Mass Transfer 2012. 48. 55-60.

16. Hussein Togun, Y.K. Salman, Hakim S. Sultan Aljibori, S.N. Kazi. "An experimental study of heat transfer to turbulent separation fluid flow in an annular passage." International Journal of Heat and Mass Transfer 54 (2011) 766-773. 